\title{
Discovering when the first early modern humans left Africa
}

Previous evidence suggested left Africa 90,000 to 120,000 years ago, but new evidence has shown this event may have occurred much earlier. (Universty of Heifa, Israel) and Professor lsrael Hershkovitz (Te Aviv University, Israel), together with their colleagues, have found a modern human fossil at Misliya cave in Israel, which 194,000 years ago. These migh be the first modern humans outside of Africa. They have shells, a variety of stone tools, abundant remains of hunted animals, and evidence for repeatedly used hearths. dates to between 177,000 and

t is accepted that Homo sapiens deserts, the Levantine corridor is the idea (humans) originated in Africa, as did location to search for evidence of early all other hominins. Hominins are the
group containing humans and human-like
area. There are several archaeological dig group containing humans and human-like area. There are several archaeological dig
species, including Neanderthals and other sites of importance in the corridor, and $\begin{aligned} & \text { species, including Neanderthals and other } \\ & \text { relatives of Homo sapiens. Humans are of importance in the corridor, and } \\ & \text { many interesting finds with significance }\end{aligned}$ the only extant member of the group of for human evolution. Professor Weinsteinhominins. This is a subsection of hominids, Evron and Professor Hershkovitz and the which are all the great apes including colleagues, have been investigating a site chimpanzees, gorillas and orangutans, colleagues, have been investigating a site as well as humans. Humans left Africa Mount Carmel, Israel. They believe they to settle all across the world, probably may have found evidence of the earliest multiple times, and to do this they would modern humans outside of Africa. have travelled the Levantine corridor. This makes the Mount Carmel - Galilee area of Israel one of the richest in the world for Middle Pleistocene Homo fossils.

THE LEVANTINE CORRIDOR The Levantine corridor is the narrow stretch of land in the Eastern Mediterranean region, at the crossroads of Africa, Asia and Europe, which would have been the route taken by early to disperse across Eurasia. Constrained

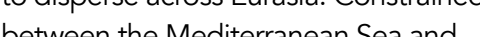

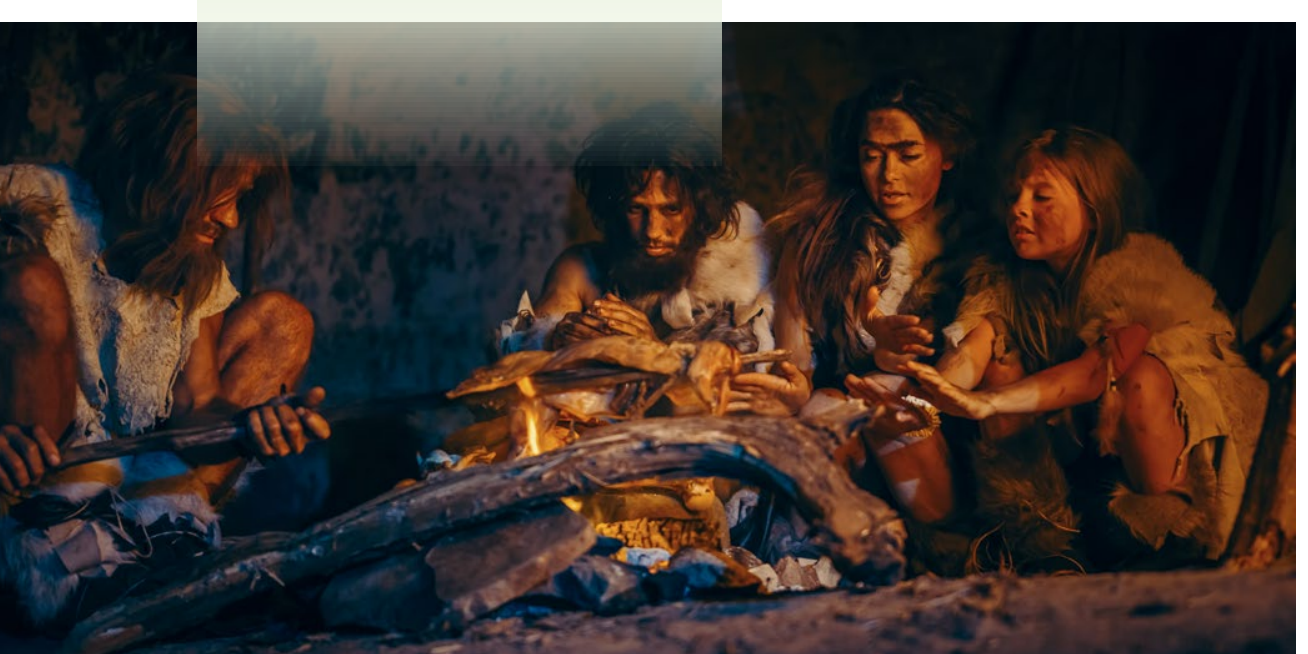

\section{HUMAN FOSSILS}

The most significant find at the Misliya cave site was the discovery of half a human upper jaw (maxilla) with attached teeth. Three different dating methods were used at three different laboratories to determine the age of the fossil. The first was uranium-thorium dating (also called U-series dating), which uses the calculate the age of calc uranium to materials such as bone. The second method was combined U-series and lectron spin resonance dating, which calculates the age of tooth enamel by the level of radiation uptake in the material. The final method used was thermoluminescence dating, which dates burnt flints by the amount of radiation they have absorbed since they were last heated. All three methods gave consisten 177,000 , nating the jaw as being between jawbone and teeth confirmed that this human. Using the term anatomically modern humans distinguishes Homo
sapiens from earlier human species as
Analysis of the physical features of the ossil belonged to an anatomically moder

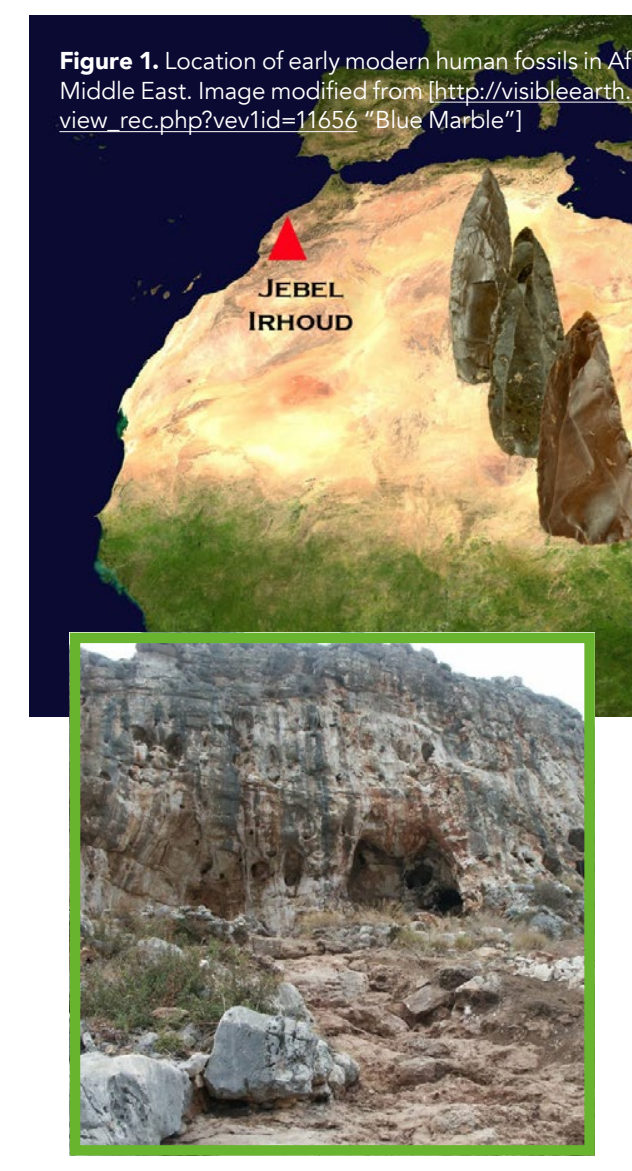

Figure 2. Misliya cave

determined by the physical characteristics. Ancestors of modern humans (earlier members of the Homo genus, such as Homo erectus) left Africa before Homo sapiens' appearance. However, the morphology of the
Misliya upper jaw and the attached tet belonging to an anatomically modern human. There are feares present the can occasionally be found in members of earlier or even contemporaneous (such as Neanderthals) hominin species, but the combination of features exhibited by the Misliya Homo is specific to Homo sapiens.

This discovery is therefore evidence that early modern humans left Africa at least 177,000 to 194,000 years ago (probably early as 250,000 years). This is considerably earlier than any other finds indicative of modern humans outside of Africa. Up unt the Misliya fossil discovery it was estim from fosils found at the neaby Shiul. and Qafzeh caves, hat early anatomically 120,000 years ago Notably, TeOse des
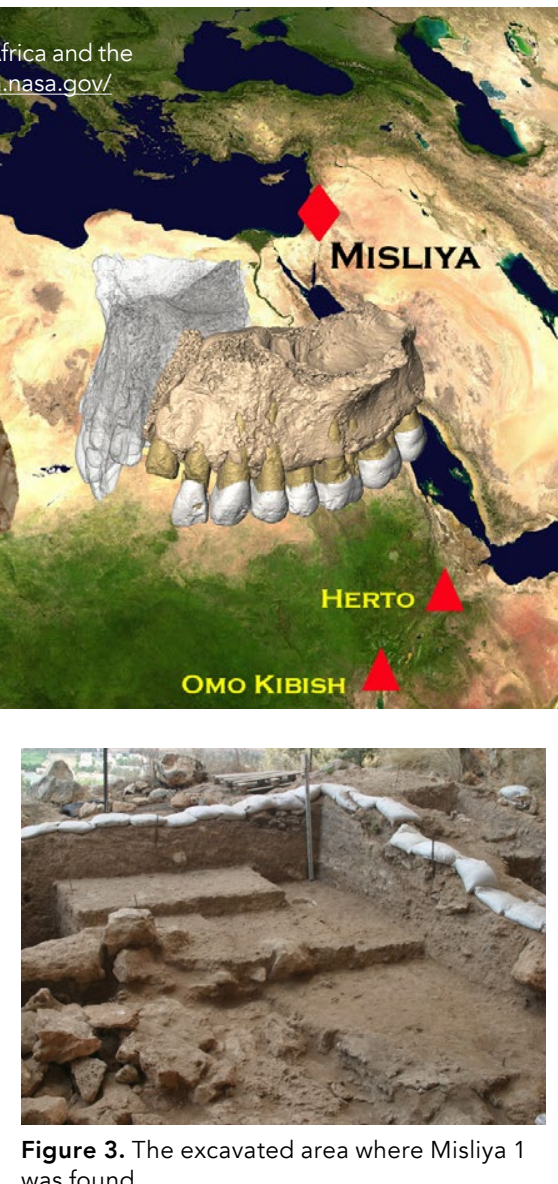

from Misliya cave suggest that this event previously thought This finding turns our ago changes our understanding of the which must have occurred much earlie If modern humans
started traveling out of Africa around 200-250,000 years ago, they must have much earlier than much earlier than

current understanding - of modern human previously appreciated somewhere
dispersal and the history of modern human
between 500,000 and 700,000 years ago. dispersal and the history of

PIECING TOGETHER THE PUZZLE Importantly, the finding that the Misliya fossil dates back 177,000 to 194,000 years

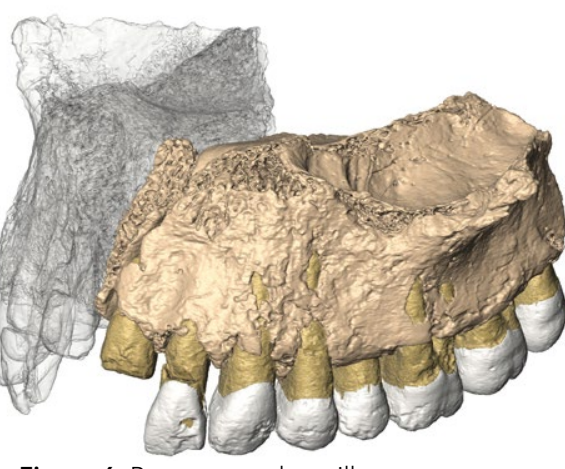

is very likely that the spread of humans in this area varied considerably, as econstructions of the environmental conditions at the time suggest that while would have been favourable, there were also dry phases that would discourage human dispersal. Therefore, it is possible that this early human fossil is evidence of one of Homo sapiens early attempts at passing into Asia. Additionally, this earlier movement of modern humans is in line with recent genetic evidence that dates the interbel Africa) to bals (which occurred outside of years ago. Significantly, together with 
projectiles (spearheads), which also form the earliest example in the region. There across Africa, which court suggogies the spread of these more sophisticated tools across Eurasia could be linked to human dispersa.

There were many tools found at Misliy cave, some of which appear to be suited for different tasks but many were multifunctional. This is an important technological shift as it indicates the development of curated tool-kits. Use-wear analysis (close examination of the wear patterns on the surfaces of tools) suggests that these tools were used for a variety of activities including the processing of both meat and plant foods, hide processing, woodworking. Surface analysis also found significant evidence of a variety were wrapped in a material such as hide, to ensure handling without risk of injury on the sharp edges. Others exhibit clear signs of hafting, i.e., when an artifact such as a blade or a point is attached to a handle or shaft to facilitate including binding, is also a significant technological advancement because it

Figure 8. Virtual imaging of Misliya 1 against
te site and typical tools

their human remains, the long cultural and environmental sequences in cave sites such as those of Mount Carmel, within heir largely Mediterranean environment speak for the potential of appreciable persistence of early populations of Homo (a)

\section{STONE TOOLS}

Tens of thousands of stone tools have of which were formed using the Levallois technology. Stone implements produced using this technology are made through the use of a complex pre-planned shaping procedure, so they are therefore considered a reflection of greater cognitive capabilities of their makers. At Misliya cave, ample employment of full-fledged (fully developed) Levallois technology, which is the earliest evidence of this technology in the area, was found in the same stratigraphic layer (sediment and debris accumulation representing the specific time episode) as the modern is further domine stone-tool assemblage is funther prolicic points, some cledy used as a handle or other grip.

HEARTHS, BEDDING, AND SHELLS The researchers have also described Misliya cave site, one of which is the evidence of the use of fire. A number of small hearths as well as one large repeatedly-used hearth have been discovered at the site. The hearths are visually distinguishable as areas where the sediment is of a different colour from the surrounding area, and analysis can reveal the presence of ashes and burnt bones or flints. The large size, density and state of burnt remains, and recurrent mode of space use around it characterise the one hearth which was used repeatedly over a considerable of long-term, repeas occupation of this site by early humans, compared to recations.

Microscopic analysis revealed evidence of plant material inside Misliya cave dated from the same period as the early material is very similar to finds from later sites, which have been suggested to be evidence of bedding or matting. It is difficult to determine with certainty that this was the use of the assemblage, but if it is bedding then this would be the earliest example to date.

A collection of shells was also found at the Mistlya cave site. There is evidence of shell collecting throughout modern huma history, and many theories for why early ranging from signalling an individul's place in socignalling snindividuals that they believed they acted as a kind of good luck charm. Particularly interesting about the shells found at Misliya cave is that they are not perforated. At sites that have been determined as later habitation of anatomically modern humans the shells collected have all been naturally perforated, which suggests that they were specifically selected for the purpose of being displayed as adomment and as a means of communication. There are also examples where perforated shells

This discovery is evidence that anatomically modern humans left Africa at least 177,000 to 194,000 years ago. tave been identified as having fibres of primitive string attached, and some bore traces of colouring in red ochre. That the Misliya shells were not perforated means that it can be inferred that the invention of string occurred 120,000 to 160,000 years ago, and that at that point early humans began to wear shells for omatrentation, something that we still do today

Taken together, the research findings of Professor Weinstein-Evron, Professor Hershkoviz and their colleagues provide important insights, not only into the ( earliest modern humans. echnological capabilities but also pushes

\section{Behind the Research}

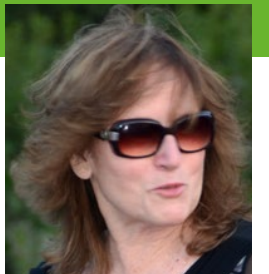

E: evron@research.haifa.ac.il T: +972 543213907

Research Objectives

The research of Mina Weistein-Evron and Israel Hershkovitz centres on
the prehistory of the Levant and Old World.

References

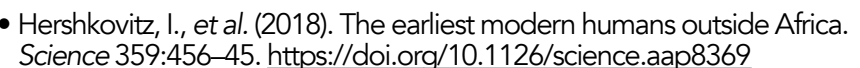

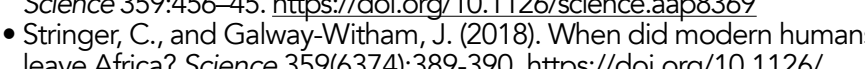
leave Affica? Science 359/(3774):389-390. https://doiorg/10.1126/

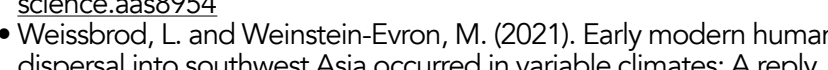
to Frumkin and Comay (2019). J Hum Evol, 102833. https:///doi.

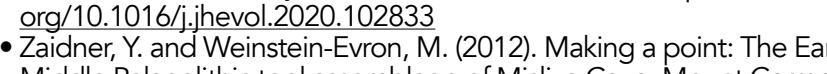
Israel. Before Farming 4:-1-23. hittos://doi.org/10.3828 bfarm.2012.4.

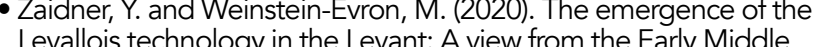

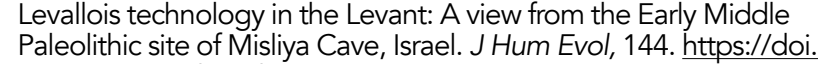

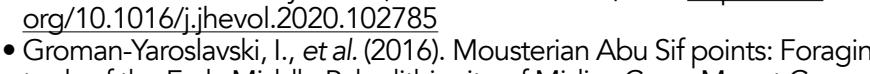

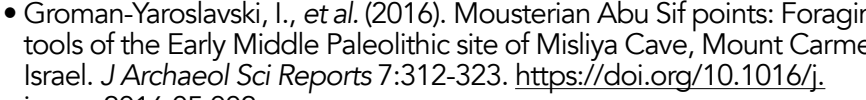
- Gasrep.2016.05.002 Early Middle Paleolithic flint tools revealed through use-wear analysis of
tools from Misiliya Cave, Mount Carmel, Irrael. J Hum Evol, 154. httos:"I

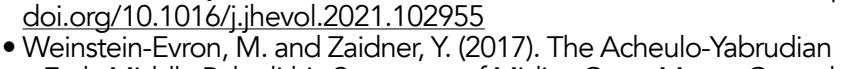

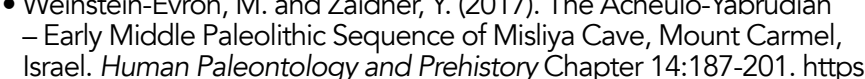

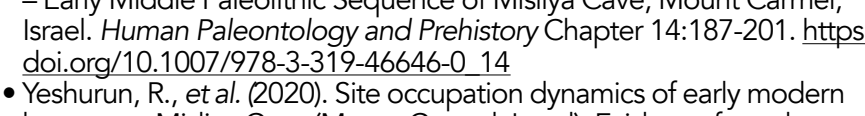

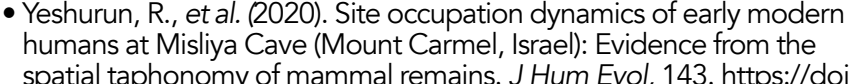

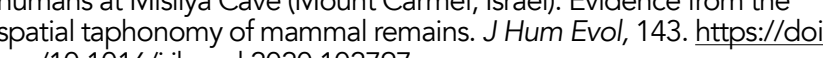

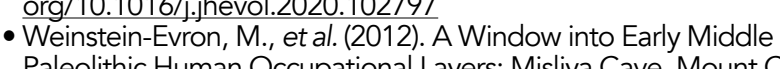

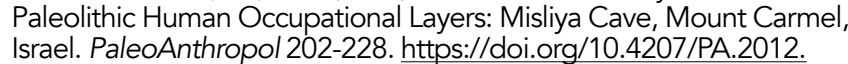
ART75

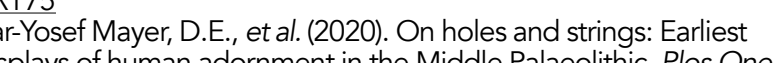
157):e023492. https:///doi.org//10.1371//journal.pone. 0234924

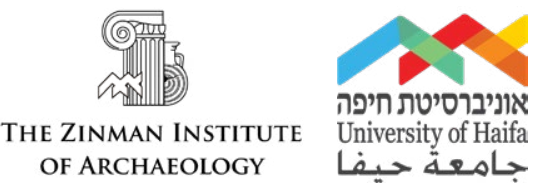

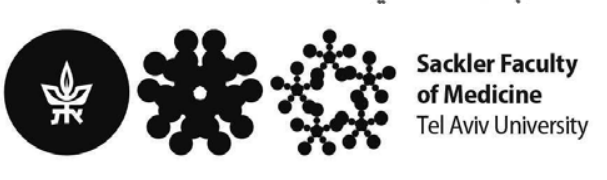

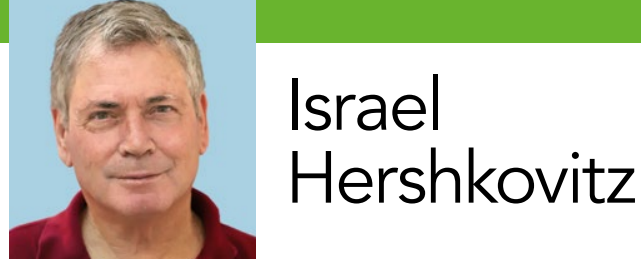

E: anatom2@tauex.tau.ac.il T: +972509967677

\section{Detail}

Bio

Mina Weinstein-Evron: Professor (emerita) of archaeology;
former Head Zinman I Istituste of Archaealog l University of Haifa; former Head of 'Ofakim': University of Hiafa honours program;
interests: prehistory, human evolution, palaeoenvirionmentsts,
technologich linnovation, symbolism, archive and heritage technological innovation, symbolism, archive and heritage
studies, history of archaeology. Recipient, Atapuerca studies, history of archaeology. Recipient, Atapuerca Values (2017).

Israel Hershkovitz: Professor (emeritus) of Anatomy and Physical Anthropology at the Department of Anatomy and David Center for Human Evolution and Biohistor, The Dan Head, The Shmunis Family Anthropology Institute; Head, Tassia and Dr Joseph Meychan Chair for the History and

Funding
Mina Weinstein-Evron: Dan David Foundation, Israel Science
Foundation, Leakey Foundation, Irene Levi-Sala Care Archaeolog, Lical Fou Foundation, the Faculty of Humanities of the
And

Israel Hershkovitz: Dan David Foundation, Shmunis Family
Anthropology Institute. Collaborators

- Mina Weinstein-Evron: Yossi Zaidner, Mathieu Duval, Tsatskin Re Helen Yeshurunas, Norbert Mercier, Alexander - Israel Hershkovitz: Gerhard W. Weber, Rachel Sarig, Hila

\section{Personal Response}

In your opinion, which of the finds at Misliya cave
is the most important or the most exciting? is the mostion, which of the finds a Misliy

II The Misliya upper jaw represents the earliest known evidence tor the presence of Homo sapiens
outside of Africa. Deciphering the Misliya migrants' intricate relationships with local populations as well as
ensuing hominin dispersals, such as the Neanderthals,
are the main challenges of our future research. are the main challenges of our future research.
The jaw was found within an extremely rich archaeological layer providing comprehensive views on the lifeways, technological innovations and
ancient environments of the caves' inhabitints The Misliya people were capable hunter-gatherers and highly advanced technologically, introducing such for flint-tool manufacture (levallois method) flint projectiles and hafting. Marine shells herald such practices in much later sites, when they were also used
as decorative elements. 